\title{
Applications of Nano Technology in Pyro Industries located in Sivakasi
}

\author{
D. Edison Selvaraj \\ Dept. of EEE \\ Panimalar Engineering College \\ Chennai, India \\ edisonsivakasi@gmail.com
}

\author{
C. Pugazhendhi Sugumaran \\ Division of High Voltage \\ Engineering, College of \\ Engineering, Guindy \\ Anna University, Chennai \\ India
}

\author{
M. Rajkumar \\ Dept. of EEE \\ Dhanalakshmi Srinivasan College \\ of Engineering and Technology \\ Mamallapuram \\ Chennai, India
}

\section{S. Geethadevi}

Dept. of EEE

Aurora Scientific and

Technological Institute

Uppal, Hyderabad, India

\author{
J.Ganesan \\ Dept. of EEE \\ Sree Sowdambika College of \\ Engineering \\ Aruppukottai, India
}

\begin{abstract}
This paper deals with the application of nano technology in the pyro industries located in Sivakasi. This paper also gives information about the geography, history, location of industries, pyro powder manufacturing companies, application of SEM, ball mill present in Sivakasi. Sivakasi is one of the most mega industrial centres present in India. Sivakasi is also called as Kutti Japan due to the enormous amount of industries present in the heart of the city. It is one of the important holy places present in the country. It is having hot climate throughout the day. Nowadays, due to El - Niño the climate conditions were changed. There is an abundant rainfall in the summer season also. This paper is useful for the students to study about the pyro industries present in sivakasi and the applications of nano technology in the pyro industries present in the city. Hereafter, the pyro industries using the nano technology for the improvement of the quality and performance of the fireworks present in Sivakasi shall also be called "Nano pyro industries" and the city can also be called as "Nano Pyro Industrial City". Pyro industries are present in the city due to the low annual rainfall and the dry climate present in the city throughout the year. The land in Sivakasi is also called as "Sulphur land" due to the heavy temperature in the city. Nowadays, the trend is changed due to the climatic changes caused by El - Niño. In the year 2015, the summer season in sivakasi was converted into rainy season by the climatic changes caused by the unstable changes in the winds from the Bay of Bengal.
\end{abstract}

Keywords: Ball Mill, Nano Powder, SEM, Pyro Industries

\section{INTRODUCTION}

This introduction chapter has three sub divisions:

1. A brief History and Geography of Sivakasi

2. A History of Industries in Sivakasi

3. A brief of Pyro industries in a Sivkasi

motors were widely used in fans, centrifugal pumps, blowers, lifts, cranes, hoists and so on. The efficiency of the induction motor depends upon the insulation used. For motors, the enamel was used for three purposes: impregnation, coating and adhesion. The efficiency of the induction motor can be increased by adding the nano fillers with the enamel which was used as coating for the windings of the motor. In this paper, the efficiency of the normal three phase squirrel cage induction motor and the $\mathrm{Al}_{2} \mathrm{O}_{3}$ nano filled enamel coated three phase squirrel cage induction motor was analyzed and the results were compared with each other [1].

\subsection{A brief History and Geography of Sivakasi}

Sivakasi has a history of more than 600 years. Its story starts from the 14 th century. Kaasi is a place where every devout Hindu is expected to visit once in their lifetime. Apart from that there are two other Kasi's in India - Tenkasi (meaning the Southern Kaasi) located near Courtallam, close to Kerala and Sivakasi (Kaasi of Siva) located at South of Madurai. It is interesting to note how Sivakasi came to be called so. The story starts as follows. Between 1428 and $1460 \mathrm{AD}$, King Harikesari Parakkirama Pandian then King of Tenkasi ruled the southern region of Madurai, with his capital at Tenkasi. He wanted to construct a temple for LORD SIVA at his place. Therefore he went to Kasi Varanasi and worshiped Lord Siva there and brought a Sivalingam from there. While returning to his place with the prized Linga a few miles past Madurai, he took rest under a groove of Vilva trees. The cow which carried Sivalingam, refused to move and also the King's wife (the Princess) attained puberty that night, which prohibited the carrying of the Linga to Tenkasi. He found that it was hard to 
reach Tenkasi in time, to install the Sivalingam and he realised that the wishes of Lord SIVA were different from his own As events thus overtook auspicious time for the already proposed plan of consecrating the Linga at Tenkasi, the king reverentially placed the Linga in the place where he had halted and proceeded to Tenkasi. The place which was sanctified by the "Sivalinga brought from Kasi", henceforth came to be called Sivakasi. Later on King Pandia and King Thirumalai Naicker did a lot for this temple, named it "KASI VISWANATHA SWAMY" Temple [1]. The period of construction was between 15th and 16th century. Aanaiappa Gnani reconstructed this temple. Under the rule of King Naickers, the temple was developed more. In 1659, the Ratham (the chariot) was constructed by Muthu Veerappa Naicker. The Title Name 'KUTTY JAPAN' was given by Mr.Jawaharlal Nehru (First Prime Minister of INDIA) to Sivakasi. 'Kutty' in Tamil means Mini. So Kutty Japan, means Mini Japan. During early 1960's India was under great famine and lots and lots of people are unemployed and it was the time, the people of Sivakasi came in hand in hand with each other to promote themselves without expecting any aid from the Government and stood on their own to achieve self reliant, high industrial growth rate (especially Matches, Fireworks, Printing and sub industries related to those industries). Until 1985 Sivakasi was a part of Ramanathapuram District. When Ramanathapuram District was trifurcated Sivakasi became a part of Virudhunagar District. It is $70 \mathrm{Kms}$ south of Madurai. Sivakasi is a black soil plains region. The soils are of poor productivity and are mainly black loamy soil (locally known as (Karisal). Cotton, pulses, oilseeds and millets, which do not require much irrigation, are the main crops grown. The climate of the Sivakasi is semi-arid tropical monsoon type. It has a high mean temperature and a low degree of humidity. The temperatures range from $20^{\circ} \mathrm{C}$ to $37^{\circ} \mathrm{C}$. April, May and June are the hottest months of the year. Sivakasi receives scanty rainfall with an annual average of $812 \mathrm{~mm}$. The South West monsoon which sets in June and lasts till August brings scanty rain. The bulk of the rainfall is received during the North East monsoon in the months of October, November and December. Vembakottai Reservoir supplies the drinking water to Sivakasi.

\subsection{A History of Industries in Sivakasi}

Like JAPAN (world leader in Electronics), Sivakasi is leader for Printing, Fireworks, Safety matches Production. So the name was given to Sivakasi. This happened only because of the people of Sivakasi, who are more dedicated committed to hard work and their togetherness to achieve attitude. The key behind this success story of each and every Sivakasians is "QUALITY with QUANTITY, HARD WORK \& Commitment to work, and Attitude of Togetherness. Hats off especially to the Nadar Community whose contributions are lot to this achievement. Like Ayya Nadar, Graha Durai Nadar, Shanmuga Nadar, KAKA Kaliappa Nadar. In 1922 Mr. P.Ayya Nadar and Mr. A.Shanmuga Nadar went to Calcutta and learnt the art of safety matches manufacture. Next year they established the company 'The South India Lucifer Match Industry'. It was the starting point of the modern industrialized Sivakasi which caters safety matches, fireworks and printing to the whole India. In turn, Sivakasi

- Contributes $80 \%$ of India's Total Safety Matches Production

- Contributes $90 \%$ of India's Total Fireworks Production

- Contributes $60 \%$ of India's Total Offset Printing Solutions.
- Is one of the high Sales / Excise / Customs Duty paying town.

- Is $100 \%$ employment achieved town (which is among a few towns in India rather world)

In Short, Sivakasi is a big industrial centre in Virudhunagar district of Tamilnadu state in India and well known all over India for its fireworks, safety matches and printing. Sivakasi is one of the highest Sales / Excise / Customs Duty paying towns in India. Enterprising and work conscious people of Sivakasi have made it one of the leading industrial towns of India in short span of time. Sivakasi is the town in India where unemployment does not exist. On witnessing the industriousness of Sivakasi people. Pandit Jawaharlal Nehru, the first Prime Minister of India optly nick named Sivakasi as "Mini Japan" ("Kutty Japan" in Tamil and "Chotta Japan" in Hindi). Sivakasi is India's fireworks hub. $90 \%$ of India's fireworks is produced in Sivakasi. A not only firework, Sivakasi is the hub of safety matches and offset printing solutions also. $80 \%$ of India's safety matches are produced in Sivakasi and $60 \%$ of India's offset printing solutions is produced in Sivakasi [2].

\subsection{A brief of Pyro industries in Sivakasi}

Sivakasi is the natural choice for fireworks production. Low rain fall and a dry climate prevailing in the Sivakasi area contribute to unabated production. What could have been consumed in three hours of the Diwali Day came to be produced in 300 days, almost with overtime jobs throughout the year. In Sivakasi the first fireworks industry was started in the early 20th century. Having achieved a measure of success in Safety Matches, Colour Matches and Star Matches, Mr. A Shanmuga Nadar and Mr. Iya Nadar ventured upon the making of sparklers -then the most popular item in the Small Fireworks family, which were at the time imported from the UK and Germany. The germinal seed for the making of modern family Fireworks or Small Fireworks was planted in the year 1934 when the Central Excise Duty on Matches was promulgated. Until the outbreak of World War II in 1939, there were only a handful of factories in Sivakasi, Trichur and rimjalakuda in Kerala State. From 1938 to 1944 the import of fireworks and firecrackers was obstructed by war. This shortage gave a fillip to the indigenous industry, which was in its infancy. During the year 1940, the Indian Explosives Rules were enacted whereby a system of licensing was introduced for manufacture, possession and sale. Thus came to be set up in the year 1940 the first organized factory with several precautions and safety measures. The shortage in the market helped these, then seasonal, factories to work even during offseason and build up stocks. With World War II coming to an end and the gateway for import of raw materials having been reopened, the indigenous industry enlarged itself. Not only the existing factories broadened their efforts, there came into existence several new units, of which National Fireworks, Kaliswari Fireworks and Standard Fireworks were prominent in the year 1942. These three factories started marketing their products throughout the length and breadth of India. These were later supplemented by new units at the average of 10 per year. What started as I or 2 factories in 1923, rose to 3 in 1942 , and by the year 1980 the number of factories had risen to 189 . By the end of 2011 the total number of factories was 850 in Sivakasi alone. Sivakasi is known throughout the world for fireworks production. $90 \%$ of India's fireworks is produced here. The fireworks industry in Sivakasi is worth between Rs 2000-6000 crore. The market for fireworks is 
likely to grow at the rate of $10 \%$ per annum. There are nearly 850 fireworks factories giving direct employment to about 40,000 workers and about 4 lakh indirect such as paper tube making, wire cutting, box making in the country side. Fireworks in Sivakasi also produce Military Weapons training items. They are used for training in armed forces. Some airports are using Sivakasi rocket to scare away birds to avoid bird hits of aircrafts.

\section{APPLICATIONS OF ALUMINIUM POWDERS IN PYRO TECHNOLOGY}

Aluminium powders are used in pyro industries for the manufacture of

- Heavy Crackers

- Garland Crackers

- Wheels

- Heavy Volcanoes

- Aerial Display Fireworks

Pyrotechnic Aluminium powders are manufactured by Sri Kaliswari Metal Powders Private Limited, Sivakasi. They are the leading manufacturers of the following products:

- Aluminium powders,

- Aluminium paste,

- Aluminium oxide powder,

- Ferro aluminium powder,

- Air atomized aluminium powder,

- Pyrotechnic aluminium powder,

- Cellular concrete aluminium powder and

- Aluminium paste in MTO, naphtha, toluene \& xylene bases,

- Aluminium oxide powder,

- Industrial metal powder

\section{MANUFACTURING PROCESSES INVOLVED IN METAL POWDER COMPANIES}

The following processes are carried out in this manufacturing company:

- Pyrotechnic Aluminium Powder or foil is propelled into a charging bin along with grease

- The milling process is carried out in the ball mill

- After a pre-determined time, the powder is pneumatically driven into a cyclone

- In the cyclone, the heavier particles get separated and are returned to the ball mill for further milling.

- $\quad$ SEM analysis of prepared powders

\subsection{Ball Milling}

Ball mill is an efficient tool for grinding many materials into fine powder. The ball mill is used to grind many kinds of mine and other materials. It is widely used in chemical industry. There are two ways of grinding: dry process and the wet process [2]. The ball mill is key equipment for regrinding. It is widely used for the cement, the silicate product glass, ceramics and etc. Here Aluminium trioxide nano material is synthesized by using ball mill to convert micro particles to nano particles.

- The pulverisetie 6 planetary monomill is universally applicable for quick dry or wet grinding of inorganic and organic samples for analysis, auality control, materials.
- The sample material is crushed and disintegrated in a grinding bowl by grinding balls.

- The grinding balls and the material in the grinding bowl are acted upon by the centrifugal forces due to the rotation of the grinding bowl about its own axis and due to the rotating supporting disc.

- As a frictional effect, the grinding balls running along the inner wall of the grinding bowl, and impact effect, the balls impacting against the opposite wall of the grinding bowl.

\subsection{SEM Analysis of Alumina powders used in Pyro Industries}

Scanning electron microscopy uses a focused high energy electron beam to image the surface of a variety of samples and collect information on morphology and elemental composition [3]. A scanning electron microscope is a highly versatile tool and can be used to study biological specimens, geological materials, nano particles, circuit boards, and many other sample types [7]. A SEM consists of an electron gun, focusing lenses, stage or specimen holder, and several types of detectors. The electron gun contains a heated metallic filament, usually tungsten, which provides the source of electrons. These electrons are accelerated toward an anode plate and then focused by condenser lenses and an objective lens. A deflector coil causes the focused electron beam to be scanned across the surface in a raster pattern [4].

There are two types of electron microscope - the scanning electron microscope (SEM) and the scanning transmission electron microscope (STEM). The samples must be conducting (in order to accelerate electrons into the sample) and hence a biological sample must have a gold layer deposited on its surface if it is to be investigated by SEM or STEM. In the STEM, the sample is a very thin specimen and contrast within the image is due to the spatial variations in intensity of the transmitted electron beam through the specimen, as the beam is raster scanned over the specimen. In SEM, the image may be produced in a number of ways from variations in the intensity of secondary electrons backscattered from the specimen through to X-ray emission produced by inelastic collisions of the primary beam with bound electrons in the specimen [6]. The idea that gave rise to the electron microscope is that, just as light is refracted and focused by an optical lens, the electron, due to its charge, will produced Cambridge Instruments Ltd.

The electrons are emitted by an incandescent cathode source, accelerated towards more positive grids through either electrostatic or magnetic field lens onto an object. The specimen is supported on a very thin film to minimize the scattering of the electrons as they pass through the sample. Depending on the thickness and composition of the object, the electron beam experiences different attenuation as a function of position. The beam travels through two more lenses before being imaged onto a fluorescent screen (in original models) or photographic plate or directly onto a scintillator placed on the face of a photomultiplier tube or a CCD device [5].

(A scintillator is a semi-transparent material, which emits a flash of light when a charged particle traverses it) The spatial resolution of this type of microscope is determined by the wavelength associated with the electrons and this wavelength may be 100,000 times smaller than optical wavelengths at the typical accelerating voltages used in electron microscopy. Figures $1-3$ show the SEM images before ball mill whereas figures $4-6$ show the SEM images after ball mill of alumina powders used in Pyro industries [8]. 


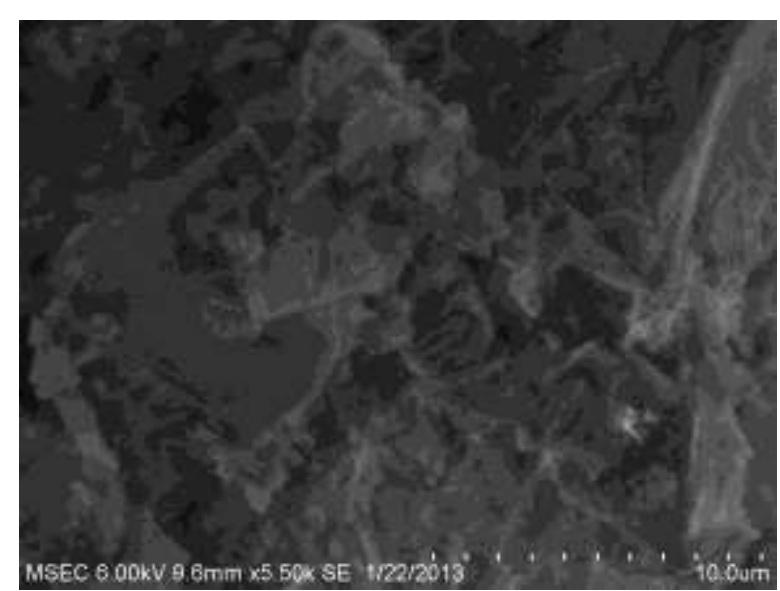

Figure 1

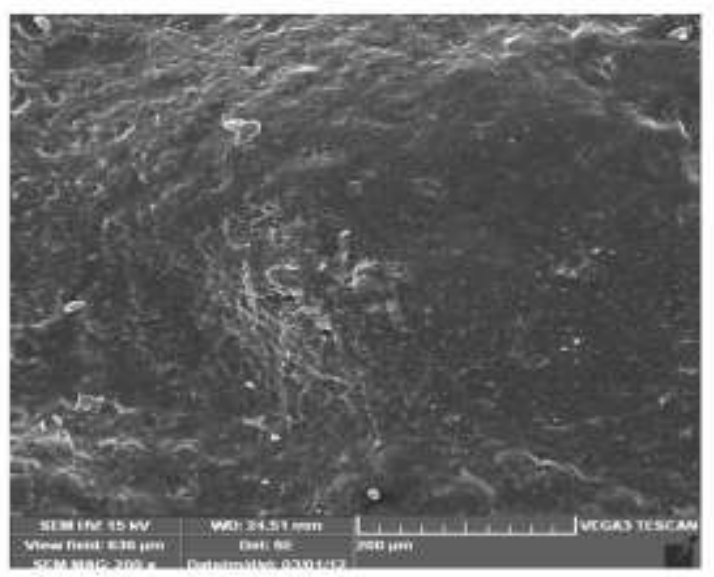

Figure 2

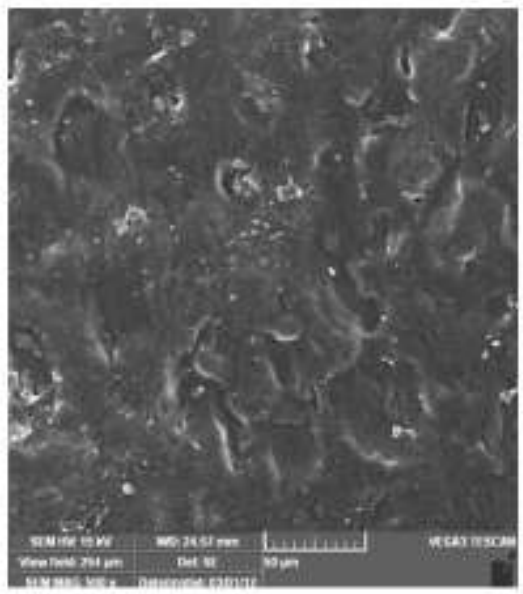

Figure 3

Figures 1 - 3 SEM analysis before ball mill

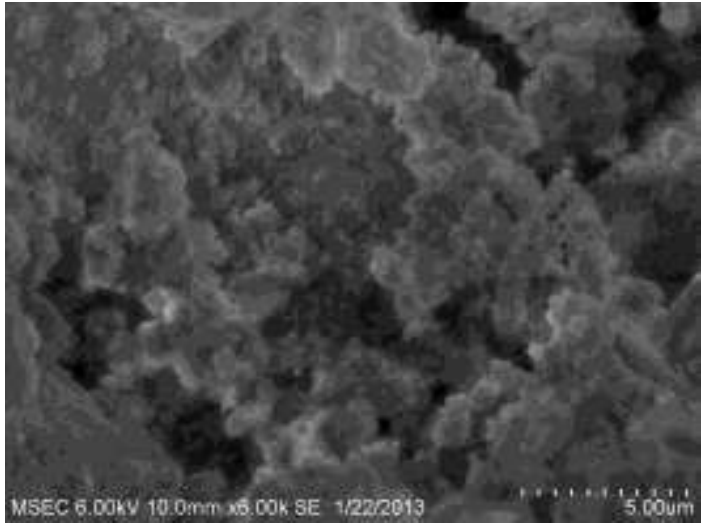

Figure 4

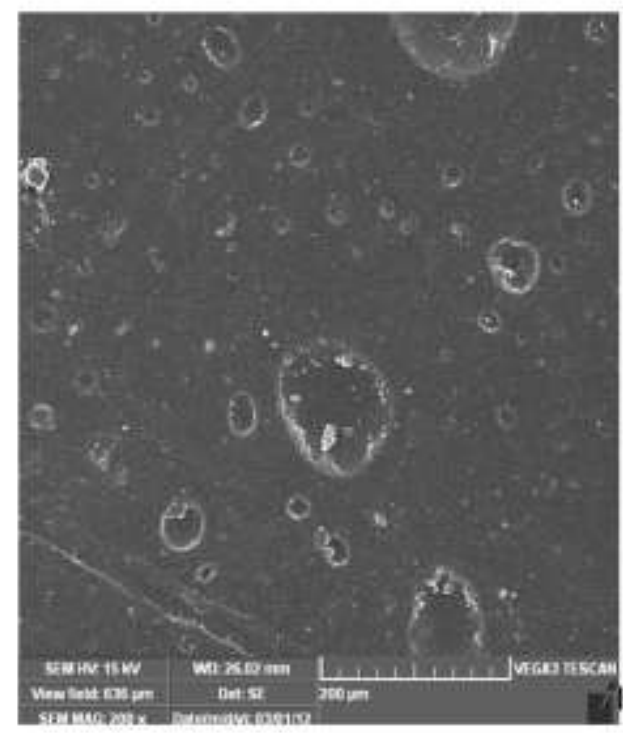

Figure 5

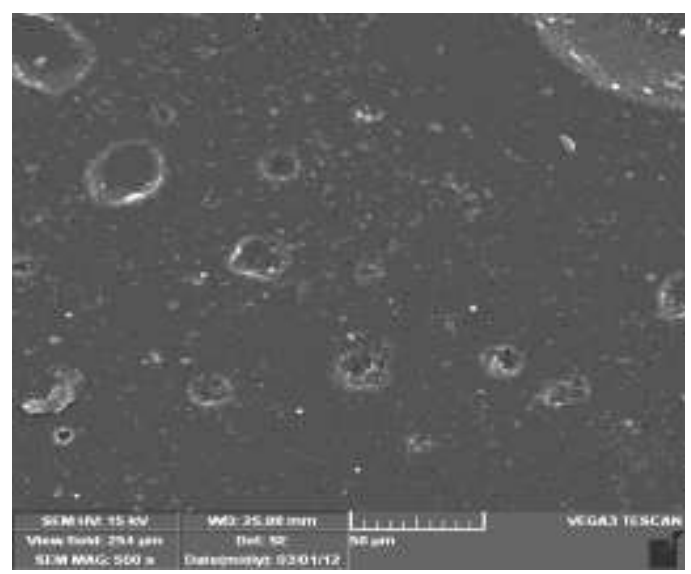

Figure 6

Figure 4 - 6 SEM Analysis after ball mill 


\section{PROBLEMS FACED BY INDUSTRIES IN SIVAKASI}

The most important problems faced by the pyro industries present in Sivakasi are

1. Introduction of china crackers in Indian Market caused some decrease in the manufacture of pyro products and selling of pyro products.

2. Heavy summer in North India caused low pyro orders from North Indians to celebrate Diwali with pyro products.

3. Small roads causing frequent traffic in Sivakasi

4. Accidents in Sivakasi due to fireworks causing fear among the workers to work in pyro industries.

5. Poorly equipped Hospitals for the treatment of persons affected by fire accidents.

6. Encroachments in roads present in Sivakasi causing heavy traffic and congestion in the city for the workers and causing road accidents in the city.

7. Poor infrastructure in the city to handle the road traffic and persons affected by fire accidents.

8. People are affected by low income for their hard work. North Indians are replacing the native workers present in Sivakasi for low wages offered to them.

Government has to take necessary steps to improve the roads, infrastructure of Sivakasi to avoid road accidents and death caused by fire accidents during the movement of persons to the Hospitals. Government has to take necessary steps to improve the wages to the workers. Government has to extend the roads, construct flyovers to avoid road accidents and to avoid traffic in the city.

\section{CONCLUSION}

This paper has dealt with the important information about the pyro industries present in Sivakasi. This paper has also suggested some necessary steps to improve the quality of pyro industries present in Sivakasi to avoid frequent accidents in the plants. Workers have to be well equipped with necessary development programmes and safety equipments to handle the explosive elements present in the industries. Infrastructure in Sivakasi has to be improved to avoid traffic, deaths during fire accidents under their movement to hospitals by the small roads present in the city. Hospitals should be well equipped with fire treatment devices and medicines. The nano technology would improve the quality and performance of pyro industries present in Sivakasi.

\section{REFERENCES}

[1] http://www.sivakasionline.com

http://www.kuttyjapan.com

Edison Selvaraj. D, et.al "Estimation of Losses on $3 \Phi$ Nano Coated Induction Motor" Applied Mechanics and Materials Vol.666 (2014) pp. 213217 (2014) Trans Tech Publications, Switzerland.

Edison Selvaraj. D, Pugazhendhi Sugumaran. C, Lieutenant Ganesan. J, Ramathilagam. J, “Analysis of Dielectric and Thermal Properties of Polyamide
Enamel Filled with Carbon Nano tubes" International Journal of Nano science, Vol.12, Issue 3, June 2013.

[5] Edison Selvaraj, D., C. Pugazhendhi Sugumaran, and A. Sivaprakash "Characterization of Electrical and Thermal Properties of Enamel Filled with Carbon Nanotubes", Proceedings of the Third International Conference on Trends in Information, Telecommunication and Computing, Springer New York, 2013.

[6] Selvaraj, D. E., Priyan, S. S., Joshi, M. R., Sugumaran, C. P., Kannan, R., Raj, R. A., Kumar, B. M., Prakash, R., Ganesan, J., Krishnamoorthi, D., \& Kumar M. R, "A Review on The Nano Fillers Used for Electrical Apparatuses”, Journal Club for Electrical Engineering (JCEE), Vol.1, Issue 1, pp 8 17, Aug 2014.

[7] Selvaraj, E. D., Priyan, S. S., Joshi, M. R., Sugumaran, C. P., Kumar, B. A., Kumar, M. A., Kumar, S. A., Khan, A. H., Kannan, R., Ganesan, J., Kumar, R., Kumar S. D, "A Review on the Fabrication Methods Used in Nano Technology for The Fabrication of Nano Fillers Used in Electrical Apparatuses", Journal Club for Electrical Engineering (JCEE), Vol.1, Issue 1, pp , Aug 2014.

[8] Joshi MR Selvaraj DE, Kumar GS, Mohan BR, Sugumaran CP, Kumar RM, Ganesan J, “A Lecture Notes for Understanding the Fundamentals of Fabrication of Nano Fillers", Journal Club for Electrical Engineering (JCEE), Vol.1, Issue 2, pp 1 16, Oct 2014. 